\title{
Efficacy of drug therapies in antihistamine refractory chronic spontaneous urticaria: Real life data
}

\author{
Mehmet Unsel
}

\begin{abstract}
Background: Omalizumab is a safe and effective treatment for antihistamine-refractory chronic spontaneous urticaria (CSU) but is insufficient in one-third of patients. For serious cases in which omalizumab is ineffective, cyclosporine or methotrexate may be preferred. Most drug trials in CSU have focused on omalizumab or cyclosporine monotherapy.

Objectives: This retrospective study evaluated responses to monotherapy or combined therapy and real-life data on the effectiveness and safety of omalizumab in antihistamine-refractory CSU.

Methods: A total of 133 patients who received omalizumab due to antihistamine-refractory CSU were evaluated in terms of 7-day urticaria activity score, total IgE, anti-thyroid peroxidase, C-reactive protein, skin prick test with aeroallergens and disease duration. Partial or nonresponders to omalizumab monotherapy were given antihistamine, omalizumab, cyclosporine, and methotrexate as combined or monotherapy.
\end{abstract}

Results: Ninety-eight (73.7\%) of the 133 patients were female and the mean age was $40.7 \pm 14.4$ years; $70.6 \%$ of the patients received omalizumab monotherapy and the others received combined or non-omalizumab monotherapy. Omalizumab monotherapy was effective in $66.9 \%$ of the patients. Of those with complete response to omalizumab monotherapy, $65.4 \%$ had early recurrence after discontinuing treatment. Treatment response was significantly better in patients who had high total IgE $(p=0.001)$. Patients with longer disease duration had significantly higher likelihood of early recurrence $(p=0.035)$.

Conclusions: Omalizumab monotherapy was as effective in real life as in placebo-controlled trials. Omalizumab was well tolerated by all patients. Treatment responses were comparable in patients treated with combined therapy and those who received monotherapy.

Key words: Omalizumab, methotrexate, cyclosporine, treatment, chronic spontaneous urticaria, efficacy, safety

\section{From:}

Department of Allergy and Immunology, Near East University, Faculty of Medicine, Nicosia, Cyprus

\author{
Corresponding author: \\ Mehmet Unsel \\ Department of Allergy and Immunology, Near East University, \\ Faculty of Medicine, Near East Boulevard \\ Lefkosa, 99138, Cyprus \\ E-mail: unselmehmet@yahoo.com
}

\section{Introduction}

Chronic spontaneous urticaria (CSU) is characterized by episodes of skin redness, swelling, and itching that last for more than 6 weeks. CSU can last for many years, with the average duration being $1-5$ years, and affects between $0.5 \%$ and $1 \%$ of the population. ${ }^{1}$ At present, second-generation antihistamines (sgAH) and omalizumab (humanized anti-immunoglobulin IgE) are widely used in the treatment of CSU. Antihistamines are the first choice of treatment because they are inexpensive, effective, and up to 4 doses can be taken per day.
However, not all patients with CSU respond to antihistamine up-dosing. In a meta-analysis investigating responses to antihistamine therapy in CSU, response rates were reported as $38.6 \%$ at standard doses and $63.2 \%$ after up-dosing in patients who did not respond to standard dosage. ${ }^{2}$ For patients who respond to antihistamine up-dosing, omalizumab (300 mg every 4 weeks, subcutaneous) is added to the treatment. ${ }^{3}$ Although omalizumab has a favorable safety profile, it is reported to be ineffective in one-third of patients treated with 
standard dosage. ${ }^{4}$ Due to the lower effectiveness and less favorable safety profiles of drugs other than omalizumab and antihistamines, the issue of how to treat nonresponders to omalizumab and sgAH is a subject of debate. The EAACI/

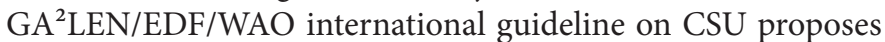
a 4-tier treatment algorithm for the treatment of urticaria. According to this algorithm, the recommended first-line therapy is a single daily dose of $\mathrm{sgAH}$, second-line therapy is up to 4 doses/day of sgAG, third-line is sgAH and omalizumab, and fourth-line therapy is sgAH and cyclosporine. The guideline emphasizes that the efficacy of sulfasalazine, methotrexate, interferon, plasmapheresis, phototherapy, intravenous immunoglobulins, and other treatment options is backed by low-quality evidence. ${ }^{3}$

Although there are placebo-controlled studies showing that omalizumab is safe and effective for patients with antihistamine-refractory $\mathrm{CSU},{ }^{5-7}$ there are very few real-life studies. There are also studies in the literature showing that cyclosporine $\left(3 \mathrm{mg} / \mathrm{kg} / \mathrm{day}^{8}\right.$ and $\left.1-5 \mathrm{mg} / \mathrm{kg} / \mathrm{day}^{9}\right)$ is effective in patients with antihistamine-refractory CSU. ${ }^{8-9}$ However, adverse effects (hypertension, abnormal serum creatinine, gastrointestinal symptoms, headache, hirsutism, infection, paresthesia) occur in up to $57 \%$ of patients even at moderate doses, limiting the use of this drug in CSU. ${ }^{9}$ A few studies conducted with small case series suggest that methotrexate is safe and beneficial for antihistamine-refractory and steroid-dependent CSU. ${ }^{10,11} \mathrm{Re}$ search on the efficacy and safety of drugs other than cyclosporine and methotrexate in the treatment of CSU is very limited. In fact, nearly all drug trials in CSU have focused on omalizumab or cyclosporine monotherapy, and studies investigating responses to combined therapies in antihistamine-refractory CSU are rare. ${ }^{12}$

The aim of this retrospective study was to determine real-life data on the effectiveness and safety of monotherapy or combined therapy in antihistamine-refractory CSU in a large patient sample.

\section{Material and Methods \\ Patient selection}

The study included 133 of 156 patients who received omalizumab for at least 3 months due to antihistamine-refractory CSU between October 2017 and May 2020. Of the 156 patients, 17 patients were excluded from the study because they continued their treatment at a different hospital after starting omalizumab and 6 patients were excluded because they did not adhere to scheduled treatment visits. Urticaria was evaluated and 7-day urticaria activity score (UAS7) was recorded monthly before each omalizumab injection. From the hospital records, data were collected regarding UAS7, laboratory analyses including total immunoglobulin E ( $\operatorname{IgE}$ ), anti-thyroid peroxidase (anti-TPO), C-reactive protein (CRP), and hemogram results, skin prick test (SPT) with common aeroallergens, age at disease onset, and disease duration. Ethical approval was obtained from Near East University Ethics committee (Reference number YDU/2020/80-1126).

\section{Treatment response}

Treatment response was defined according to UAS7 and clinical findings. UAS7 of 0 was regarded as complete response (CR); UAS7 of 1-6 as well-controlled response (WCR); UAS7 of 7-27 and/or less severe but persistent urticaria as partial response (PR), and UAS7 of 28-42 and/or no reduction in urticaria severity or continuing need for systemic glucocorticoids to suppress urticaria as nonresponse (NR). Patients with complete and well-controlled responses to omalizumab monotherapy were classified as responders, patients with partial response as partial responders, and those with no response as nonresponders.

\section{Treatment protocol}

Patients with antihistamine-refractory CSU were started on $300 \mathrm{mg}$ of omalizumab administered at 4-week intervals. Antihistamine was discontinued in patients with complete urticaria regression after starting omalizumab therapy. Patients whose urticaria recurred after cessation of antihistamine were again given up to 4 doses of antihistamine per day depending on their condition.

For those who partially responded to regular omalizumab and up to 4 doses of sgAH per day, cyclosporine $(2.5 \mathrm{mg} / \mathrm{kg} /$ day $)^{13}$ or methotrexate (15 mg/week, ${ }^{10,11}$ subcutaneous) was added to the treatment regimen.

Omalizumab was discontinued if no response was seen after at least 3 months of omalizumab and sgAH therapy.

Omalizumab dosing was increased to $300 \mathrm{mg}$ at 2-week intervals in patients who responded to omalizumab but whose urticaria recurred before the following injection and in those who did not respond to treatment with omalizumab and antihistamine and cyclosporine or methotrexate. ${ }^{14}$

Omalizumab therapy was discontinued after 24 weeks in patients who showed complete response and was reinitiated if urticaria recurred after discontinuation.

\section{Recurrence}

In patients who responded to omalizumab monotherapy, treatment was discontinued after 24 weeks. Early recurrence was defined as the reappearance of urticaria in these patients within 3 months of the last injection.

\section{Adverse effects}

When collecting the study data, all patients were asked whether they experienced any problems related to the medication. Blood analyses (hepatitis markers, hemogram, kidney and liver function tests, blood lipids, magnesium) and blood pressure monitoring were done before introducing cyclosporine or methotrexate and periodically during treatment.

\section{Statistical analysis}

Continuous variables are reported as mean, standard deviation (SD), minimum, and maximum values. (or medians and interquartile ranges in case of serious deviations from normality). Categorical data are reported as frequency and percentage values. Variables were tested for normal data distribution using the Kolmogorov-Smirnov test. Considering clinical response and relapses, Student's two-sample t-test or 
Mann-Whitney nonparametric test was used as appropriate for comparisons of continuous variables between groups. Multiple comparisons after significant Kruskal-Wallis test were performed with Dunn's test and $p$ values were adjusted according to Bonferroni correction. Associations between categorical variables were evaluated using Pearson's chi-square or Fisher's exact test. Nonparametric Brunner and Langer model (LD-F1F1-LD-F1) was used to test UAS7 score changes using a web-based software ( $\mathrm{R}$ software, version 3.5.2, package: nparLD, R Foundation for Statistical Computing, Vienna, Austria; http://r-project.org). C-reactive protein (CRP) concentrations were dichotomized as $>5.0$ and $\leq 5.0 \mathrm{mg} / \mathrm{L}$ and IgE concentrations ${ }^{15}$ as $>100$ and $\leq 100 \mathrm{IU} / \mathrm{ml}$ for comparisons. SPT was considered positive if results indicated aeroallergen sensitization.

Statistical significance was set at $p<0.05$. Data were analyzed using IBM SPSS Statistics version 21.0 (IBM Corp., Armonk, NY).

\section{Results}

A total of 133 patients with CSU treated with omalizum$\mathrm{ab}$ were included in the study. Of these, $73.7 \%$ were female. One-hundred thirty (97.7\%) of the patients had CSU and the others had CSU presenting with angioedema without wheals. The patients' mean age was $40.7 \pm 14.4(12-86)$ years. Of the patients who underwent SPT, 27 (40.9\%) were sensitized to at least one of the common aeroallergens (grass, weeds, trees, mold, house dust mites). The blood analyses, and all demographic and clinical data of the patients are provided in detail in Table 1.

Table 1. Demographic and clinical characteristics of study patients

\begin{tabular}{|c|c|}
\hline Patients (n) & 133 \\
\hline Age, years, mean \pm SD (range) & $40.7 \pm 14.4(12-86)$ \\
\hline Female, n (\%) & $98(73.7)$ \\
\hline \multicolumn{2}{|l|}{ Diagnosis, } \\
\hline CSU, n (\%) & $130(97.7)$ \\
\hline $\begin{array}{l}\text { CSU presenting with angioedema without } \\
\text { wheals, } \mathrm{n}(\%)\end{array}$ & $3(2.3)$ \\
\hline Age at onset, years, mean \pm SD (range) & $34.5 \pm 13.7(2-81)$ \\
\hline \multicolumn{2}{|l|}{ Disease duration } \\
\hline Months, median (range) & $6(0.5-360)$ \\
\hline$>1$ year, $\mathrm{n}(\%)$ & $46(34.6)$ \\
\hline Concomitant angioedema, n (\%) & $92(69.2)$ \\
\hline Aeroallergen skin prick test, $\mathrm{n}$ & 67 \\
\hline Positive, n (\%) & $27(40.9)$ \\
\hline Total IgE (IU/ml), n & 109 \\
\hline High (> 100), n (\%) & $63(57.8)$ \\
\hline Median (range) & $130(0.8-2500)$ \\
\hline
\end{tabular}

Table 1. (Continued)

\begin{tabular}{cc}
\hline CRP $(\mathrm{mg} / \mathrm{L}), \mathrm{n}$ & 58 \\
High $(>5), \mathrm{n}(\%)$ & $21(36.2)$ \\
Median (range) & $2.75(0.03-55)$ \\
Anti-TPO (IU/ml), n & 66 \\
High ( $\geq 34), \mathrm{n}(\%)$ & $17(25.8)$ \\
Median (range) & $14.15(5-4339)$ \\
UAS7, n & 129 \\
\hline Median (range) & $42(12-42)$ \\
\hline
\end{tabular}

SD: Standard deviation, CSU: Chronic spontaneous urticaria, IgE: Immunoglobulin E, CRP: C-reactive protein, Anti-TPO: Anti-thyroid peroxidase, UAS7: 7-day urticaria activity score

In $4(3.1 \%)$ of the 133 patients treated with omalizumab, the dose was increased to $600 \mathrm{mg}$ due to inadequate control by the standard dose. Median duration of omalizumab therapy was $6(3-60)$ months. There were 89 responders $(66.9 \%)$, 29 partial responders $(21.8 \%)$, and 15 nonresponders $(11.3 \%)$. Adverse effects were observed in 5 patients $(3.7 \%)$. Three patients reported pain at the injection site and 2 patients reported upper extremity pain; no patients experienced adverse systemic effects requiring discontinuation of treatment. Of the patients who responded to omalizumab monotherapy, $65.4 \%$ experienced early recurrence after discontinuation of treatment (Table 2).

Table 2. Results of omalizumab monotherapy

\begin{tabular}{|c|c|}
\hline Patients (n) & 133 \\
\hline \multicolumn{2}{|l|}{ Dose, $\mathrm{n}(\%)$} \\
\hline $300 \mathrm{mg}$, every 4 weeks & $129(96.9)$ \\
\hline $300 \mathrm{mg}$, every 2 weeks & $4(3.1)$ \\
\hline Treatment duration, months, median (range) & $6(3-60)$ \\
\hline \multicolumn{2}{|l|}{ Treatment response, $\mathrm{n}(\%)$} \\
\hline $\mathrm{CR}$ & $74(55.6)$ \\
\hline WCR & $15(11.3)$ \\
\hline $\mathrm{PR}$ & $29(21.8)$ \\
\hline NR & $15(11.3)$ \\
\hline Early recurrence, n (\%) & $51(65.4)$ \\
\hline Adverse effects, n (\%) & $5(3.7)$ \\
\hline UAS7, n & 129 \\
\hline Initial, median (range) & $42(12-42)$ \\
\hline Final, median (range) & $0.000(0.00-42)$ \\
\hline Initial vs. final, $\mathrm{P}$ value & $\mathrm{P}<0.001$ \\
\hline
\end{tabular}

CR: Complete response, WCR: Well-controlled response, PR: Partial response, NR: Nonresponse, UAS7: 7-day urticaria activity score 
Comparison of demographic, clinical, and laboratory parameters of responders $(n=89)$, partial responders $(n=29)$, and nonresponders $(\mathrm{n}=15)$ to omalizumab monotherapy showed that total IgE level was significantly higher in the responder group compared to the non-responder group ( $p=$ 0.001). The proportion of patients with elevated anti-TPO was significantly higher in the nonresponder group compared to the responder group $(p=0.025)$. Similarly, median anti-TPO level was higher in the non-responder group compared to the responder group, but the difference was not statistically significant $(p=0.079)$ (Table 3).
Median disease duration time was 5 (2-108) months for patients with early recurrence after omalizumab discontinuation $(\mathrm{n}=51)$ compared to $12(0.5-360)$ months for those without early recurrence $(n=27)(p=0.035)$ (Table 4). In addition, the rate of early relapse was higher among patients with disease duration longer than 1 year compared to those with disease duration of less than 1 year $(81.5 \%$ vs. $56.9 \%$, $p$ $=0.030)$. The rate of positive skin prick test for aeroallergens was significantly higher among patients who did not have early recurrence $(p=0.047)$ (Table 4$)$.

Table 3. Characteristics of responders, partial responders, and nonresponders to omalizumab monotherapy

\begin{tabular}{|c|c|c|c|c|}
\hline Patients (n) & Responders (89) & Partial responders (29) & Nonresponders (15) & $P$ value \\
\hline Age, years, Mean \pm SD (range) & $40.6 \pm 14.6(12-86)$ & $40 \pm 14.4(18-74)$ & $42.5 \pm 13.4(24-66)$ & 0.856 \\
\hline Female, n (\%) & $64(71.9)$ & $22(75.9)$ & $12(802)$ & 0.770 \\
\hline Age at onset, years, Mean \pm SD (range) & $33.6 \pm 13.5(2-81)$ & $34.9 \pm 14.4(16-73)$ & $38.8 \pm 13.1(20-61)$ & 0.468 \\
\hline Disease duration, months, Median (range) & $6(0.5-360)$ & $7(1-108)$ & $5(1.5-120)$ & 0.639 \\
\hline Disease duration, > 1 year, n (\%) & $34(73.9)$ & $8(17.4)$ & $4(8.7)$ & 0.459 \\
\hline Concomitant angioedema, n (\%) & $59(66.3)$ & $21(72.4)$ & $12(80)$ & 0.518 \\
\hline SPT positivity with aeroallergens, n (\%) & $25(49)$ & $3(23.1)$ & $0(0)$ & 0.089 \\
\hline \multicolumn{5}{|l|}{ Total IgE (IU/ml) } \\
\hline High (> 100), n (\%) & $49(69)^{*}$ & $11(47.8)$ & $3(20)^{*}$ & 0.001 \\
\hline Median (range) & $142(1.5-1575)^{*}$ & $90(0.8-2500)$ & $10(2-1283)^{*}$ & 0.001 \\
\hline \multicolumn{5}{|l|}{ CRP (mg/L) } \\
\hline High $(>5), \mathrm{n}(\%)$ & $14(35)$ & $2(20)$ & $5(62.5)$ & 0.169 \\
\hline Median (range) & $2.55(0.03-55)$ & $1.95(0.1-8.9)$ & $5.5(0.5-33)$ & 0.228 \\
\hline \multicolumn{5}{|l|}{ Anti-TPO (IU/ml) } \\
\hline High $(\geq 34), n(\%)$ & $7(17.1)^{*}$ & $4(26.7)$ & $6(60)^{*}$ & 0.025 \\
\hline Median (range) & $13.8(5-4339)$ & $13.8(6.8-439)$ & $53.7(5.1-160.2)$ & 0.079 \\
\hline UAS7, initial, median (range) & $42(12-42)$ & $42(13-42)$ & $42(28-42)$ & 0.094 \\
\hline
\end{tabular}

SD: Standard deviation, IgE: Immunoglobulin E, CRP: C-reactive protein, Anti-TPO: Anti-thyroid peroxidase, UAS7: 7-day urticaria activity score, SPT: Skin prick test

${ }^{\star}$ Indicates groups with statistically significant difference in pairwise comparisons

Table 4. Characteristics of patients with and without early relapse

\begin{tabular}{|c|c|c|c|}
\hline Patients (n) & No early recurrence (27) & Early recurrence (51) & $P$ value \\
\hline Age, years, mean $\pm \mathrm{SD}$ (range) & $37.9 \pm 17.2(12-86)$ & $41.7 \pm 12.1(22-84)$ & 0.209 \\
\hline Female, n (\%) & $20(74.1)$ & $40(78.4)$ & 0.664 \\
\hline Age at onset, years, mean \pm SD (range) & $30.2 \pm 16(2-73)$ & $35 \pm 11.5(16-81)$ & 0.196 \\
\hline Disease duration, months, mean $\pm \mathrm{SD}$ (range) & $5(2-108)$ & $12(0.5-360)$ & 0.035 \\
\hline Concomitant angioedema, n (\%) & $19(70.4)$ & $36(70.6)$ & 0.984 \\
\hline SPT positivity with aeroallergens, n (\%) & $10(66.7)$ & $9(32.1)$ & 0.047 \\
\hline \multicolumn{4}{|l|}{ Total IgE (IU/ml) } \\
\hline High $(>100), \mathrm{n}(\%)$ & $13(61.9)$ & $23(59)$ & 0.825 \\
\hline Median (range) & $132(11-1000)$ & $141(1.5-1383)$ & 0.757 \\
\hline
\end{tabular}


Table 4. (Continued)

\begin{tabular}{|c|c|c|c|}
\hline Patients (n) & No early recurrence (27) & Early recurrence (51) & $P$ value \\
\hline \multicolumn{4}{|l|}{ CRP (mg/L) } \\
\hline $\operatorname{High}(>5), \mathrm{n}(\%)$ & $3(50)$ & $3(18.8)$ & 0.143 \\
\hline Median (range) & $4(0.1-34)$ & $2.4(0.03-22.35)$ & 0.606 \\
\hline \multicolumn{4}{|l|}{ Anti-TPO (IU/ml) } \\
\hline High ( $\geq 34), \mathrm{n}(\%)$ & $1(14.3)$ & $5(25)$ & 0.557 \\
\hline Median (range) & $11.4(10.7-94.1)$ & $15.5(6.3-4339)$ & 0.097 \\
\hline UAS7, initial, median (range) & $39(13-42)$ & $42(13-42)$ & 0.169 \\
\hline
\end{tabular}

SD: Standard deviation, IgE: Immunoglobulin E, CRP: C-reactive protein, Anti-TPO: Anti-thyroid peroxidase, UAS7: 7-day urticaria activity score, SPT: Skin prick test

Seven of 44 patients who showed partial response or nonresponse to omalizumab monotherapy refused treatment with cyclosporine or methotrexate due to the potential adverse effects. Omalizumab, sgAH, cyclosporine, and methotrexate were given as combined therapy or monotherapy to the remaining 37 patients. Thirty-two patients received combined therapy, 4 received cyclosporine monotherapy and 1 received methotrexate monotherapy. Of the 32 patients who received combined therapy, 29 (90.6\%) were given sgAH and $28(87.5 \%)$ were given omalizumab. Omalizumab dose was increased to $600 \mathrm{mg} / \mathrm{month}$ in $4(14.2 \%)$ of 28 patients due to nonresponse.

Evaluated overall, of the 126 patients who continued treatment, $89(70.6 \%)$ received omalizumab monotherapy, $32(25.4 \%)$ received combined therapy, $4(3.2 \%)$ received cyclosporine monotherapy, and $1(0.8 \%)$ received methotrexate monotherapy. A total of 121 (96\%) of the $126 \mathrm{sgAH}$-refractory patients were responsive to combined or monotherapy (Table 5). Initial median UAS7 was 42 (12-42) in the monotherapy group and $42(13-42)$ in the combined therapy group, while final median UAS7 values were $0(0-6)$ and $0.5(0-42)$, respectively. Although there was no difference in initial measurements between the monotherapy and combined therapy groups ( $p=0.909)$, the change between initial and final UAS7 measurements was greater in the monotherapy group compared to the combined therapy group (interaction effect, $p=$ $0.014)$. However, amount of the change did not differ statistically between the groups $(p=0.124)$. Of 12 patients started on cyclosporine, only 6 were able to continue; 3 patients (25\%) discontinued cyclosporine therapy due to nonresponse and $5(41.7 \%)$ due to adverse effects. Adverse effects observed in patients using cyclosporine included elevated blood pressure in 3 patients, hirsutism in 1, hyperlipidemia in 1, and gingival hypertrophy in 3 patients. Nine patients were started on methotrexate. All patients received methotrexate at a dose of $15 \mathrm{mg} /$ week. Of these, methotrexate was ineffective in $2 \mathrm{pa}-$ tients $(22.2 \%)$. Seven $(77.7 \%)$ of the patients continued using methotrexate, while the others discontinued it due to ineffectiveness and/or adverse effects. Slight elevation in liver function tests was observed in 1 patient (11.1\%). Details of the patients' cyclosporine and methotrexate therapy are provided in Table 5.
Table 5. Treatment distribution and responses in all patients

\begin{tabular}{|c|c|}
\hline Patients, n & 126 \\
\hline \multicolumn{2}{|l|}{ Treatment distribution, $\mathrm{n}(\%)$} \\
\hline Omalizumab & $89(70.6)$ \\
\hline Omalizumab + sgAH (1 tablet/day) & $8(6.3)$ \\
\hline Omalizumab $+\operatorname{sgAH}$ ( $\geq 2$ tablets/day) & $16(12.7)$ \\
\hline Omalizumab + cyclosporine & $1(0.8)$ \\
\hline Omalizumab + methotrexate & $2(1.6)$ \\
\hline $\begin{array}{l}\text { Omalizumab }+\operatorname{sgAH}(\geq 2 \text { tabets/day })+\text { meth- } \\
\text { otrexate }\end{array}$ & $1(0.8)$ \\
\hline Cyclosporine $+\operatorname{sgAH}$ ( $\geq 2$ tablets/day) & $1(0.8)$ \\
\hline Methotrexate $+\operatorname{sgAH}(\geq 2$ tablets/day) & $3(2.4)$ \\
\hline Cyclosporine & $4(3.2)$ \\
\hline Methotrexate & $1(0.8)$ \\
\hline \multicolumn{2}{|l|}{ Treatment response, $\mathrm{n}(\%)$} \\
\hline CR & $98(77.8)$ \\
\hline WCR & $23(18.3)$ \\
\hline PR & $4(3.2)$ \\
\hline NR & $1(0.8)$ \\
\hline \multicolumn{2}{|l|}{ Omalizumab therapy } \\
\hline Treatment duration, months, median (range) & $6(3-60)$ \\
\hline \multicolumn{2}{|l|}{ Dose, n (\%) } \\
\hline $300 \mathrm{mg}$, every 4 weeks & $118(93.7)$ \\
\hline $300 \mathrm{mg}$, every 2 weeks & $8(6.3)$ \\
\hline \multicolumn{2}{|l|}{ Cycloporine therapy } \\
\hline Patients, n & 12 \\
\hline Patients who continued treatment, n (\%) & $6(50)$ \\
\hline Treatment duration, months, median (range) & $6.5(2-15)$ \\
\hline Nonresponders, n (\%) & $3(25)$ \\
\hline Adverse effects, $\mathrm{n}(\%)$ & $5(41.6)$ \\
\hline
\end{tabular}


Table 5. (Continued)

\begin{tabular}{|cc|}
\hline Methotrexate therapy & \\
\hline Patients, $\mathrm{n}$ & 9 \\
\hline Patients who continued treatment, $\mathrm{n}(\%)$ & $7(77.7)$ \\
\hline Treatment duration, months, median (range) & $5(1.5-7.5)$ \\
\hline Nonresponders, $\mathrm{n}(\%)$ & $2(22.2)$ \\
\hline Adverse effects, $\mathrm{n}(\%)$ & $1(11.1)$ \\
\hline UAS7, $\mathrm{n}$ & 123 \\
\hline Initial, median (range) & $42(12-42)$ \\
\hline Final, median (range) & $0.0000(0.00-42)$ \\
\hline Initial vs. final, $P$ value & $P<0.001$ \\
\hline
\end{tabular}

sgAH: Second-generation antihistamine, CR: Complete response, WCR: Well-controlled response, PR: Partial response, NR: Nonresponse, UAS7: 7-day urticaria activity score.

\section{Discussion}

As omalizumab is increasingly used in the treatment of CSU, there has been a corresponding increase in real-life studies of its efficacy and safety in recent years. However, most of these studies have involved small patient groups. There are very few real-life studies conducted with large patient samples (> 100).,16-18 Unlike other studies, ours is the first to investigate the effectiveness and safety of omalizumab monotherapy and combined therapy for the treatment of sgAH-refractory CSU in a large patient group $(n=133)$.

In placebo-controlled phase III trials, $300 \mathrm{mg}$ omalizumab every 4 weeks was reported to reduce UAS7 to 0 in $43-48 \%$ of patients and to $\leq 6$ in $56-66 \%$ of patients..$^{5-7}$ In these study groups, suspected drug-related adverse effects were observed in up to $17.3 \%$ of patients, though no significant difference in adverse effects was detected between the placebo and treatment groups. Common adverse effects included nausea, nasopharyngitis, cough, sinusitis, headache, back pain, and fatigue. Omalizumab monotherapy response rates in the present study were higher compared to those reported in placebo-controlled trials (UAS7 $=0: 55.6 \%$ vs. $43-48 \%$; UAS7 $\leq 6$ : $66.9 \%$ vs. $56-66 \%)$ and the rate of adverse effects was much lower (3.7\% vs. $17.3 \%) .^{5-7}$

In a retrospective study investigating the effectiveness and safety of omalizumab, 67\% of 137 patients with CSU were evaluated as responders, $22 \%$ as partial responders, and $10 \%$ as nonresponders. Systemic adverse events (suspicious allergic reactions, gastrointestinal symptoms, injection site reactions, headache, weakness, fatigue, and arthritis) were observed in $14 \%$ of patients. ${ }^{16}$ The treatment responses observed in that study were very similar to the omalizumab monotherapy responses seen in the present study, but the rate of adverse effects was much higher (Table 6). In another dual-center retrospective omalizumab trial involving 106 patients with CSU, CR was reported in $47.2 \%$, WCR in $33 \%$, PR in $9.4 \%$, and NR in $10.4 \%$ of the patients. Adverse effects were observed in $6.6 \%$ of patients. ${ }^{17}$ Compared to our study, that study had a lower CR rate $(47.2 \%$ vs. $55.6 \%)$, higher WCR rate $(33 \%$ vs. $11.3 \%)$, and similar NR rate $(10.4 \%$ vs. $11.3 \%)$, while the prevalence of adverse events was higher (Table 6).

In a prospective omalizumab efficacy study completed by 84 of the 117 enrolled patients, $41.9 \%$ of the patients responded to treatment (UAS7 $\leq 6$ ) and $12.8 \%$ reported adverse effects. ${ }^{18}$ The most common adverse effects were weight loss, arthralgia, palpitations, headache, and fatigue. No significant relationship between treatment response and the presence of angioedema, total IgE, or CRP was observed in that study. Compared to our study, the efficacy of omalizumab was lower while the rate of adverse effects was higher (Table 6). In another prospective phase IV open-label trial of omalizumab efficacy and safety completed by 124 of 136 enrolled patients, the treatment response rate (UAS7 $\leq 6$ ) was $67.7 \% .{ }^{4}$ However, adverse effects associated with omalizumab were observed in $36.8 \%$ of patients. Although the rate of treatment response to

Table 6. Comparison of retrospective and prospective studies of omalizumab monotherapy

\begin{tabular}{|c|c|c|c|c|c|c|c|}
\hline Study & $\begin{array}{c}\text { Patient } \\
\text { number, } \\
\text { n }\end{array}$ & $\begin{array}{c}\text { Omalizumab } \\
\text { dose, } \mathrm{mg} / 4 \\
\text { weeks }\end{array}$ & $\begin{array}{c}\text { Responders, } \\
\%\end{array}$ & $\begin{array}{c}\text { Partial } \\
\text { responders, } \\
\%\end{array}$ & $\begin{array}{l}\text { Nonresponders, } \\
\%\end{array}$ & $\begin{array}{c}\text { Adverse } \\
\text { event } \\
\text { rate, } \%\end{array}$ & Reported adverse events \\
\hline${ }^{\star}$ Present study & 133 & $\begin{array}{c}300(\mathrm{n}: 129) \\
600(\mathrm{n}: 4)\end{array}$ & 66.9 & 21.8 & 11.3 & 3.7 & Injection site and upper extremity pain \\
\hline${ }^{\star}$ Ghazanfar at al. ${ }^{16}$ & 137 & 300 & 67 & 22 & 10 & 14 & $\begin{array}{l}\text { Suspicious allergic reactions, gastro- } \\
\text { intestinal symptoms, injection site } \\
\text { reactions, headache, weakness, fatigue, } \\
\text { and arthritis }\end{array}$ \\
\hline${ }^{*}$ Salman et al. ${ }^{17}$ & 106 & $\begin{array}{l}300(\mathrm{n}: 103) \\
150(\mathrm{n}: 3)\end{array}$ & 80.2 & 9.4 & 10.4 & 6.6 & $\begin{array}{l}\text { Urticaria activation, hair loss, anxiety, } \\
\text { bronchospasm, and headache }\end{array}$ \\
\hline${ }^{* *}$ Ghazanfar at al. ${ }^{18}$ & 84 & 300 & 41.9 & - & - & 12.8 & $\begin{array}{l}\text { Weight loss, arthralgia, palpitations, } \\
\text { headache, and fatigue }\end{array}$ \\
\hline${ }^{*}$ Bérard at al. ${ }^{4}$ & 124 & 300 & 67.7 & - & - & 36.8 & $\begin{array}{l}\text { Headache, weakness, arthralgia, } \\
\text { weight gain, alopecia, and nausea. }\end{array}$ \\
\hline${ }^{\star}$ Marzano at al. ${ }^{24}$ & 470 & 300 & 70.2 & 20.2 & 9.6 & - & - \\
\hline
\end{tabular}

${ }^{\star}$ Retrospective study, ${ }^{* *}$ Prospective study. 
omalizumab in that trial was very close to our results with omalizumab monotherapy, the reported rate of adverse effects was much higher (Table 6).

The inefficacy of omalizumab monotherapy in approximately one-third of patients with $\mathrm{CSU}^{4}$ and the recurrence of urticaria after treatment discontinuation in omalizumab responders have prompted researchers to identify clinical and laboratory parameters that may be associated with treatment response and recurrence. While the results of some studies indicated that there was no significant relationship between angioedema and treatment response, ${ }^{4,18}$ another study suggested that angioedema may be a negative predictor of treatment response. ${ }^{19}$ Two studies suggested that patients with high total IgE levels may respond better to treatment ${ }^{20,21}$ and one study indicated that high CRP level was associated with poorer treatment response, ${ }^{22}$ whereas no significant relationship between treatment response and IgE or CRP levels was observed in another study. ${ }^{18}$ One study suggested that the likelihood of recurrence after treatment discontinuation was higher among patients with high total IgE level..$^{23}$ These contradictory results may be related to the patient groups being too small or highly variable in number $(\mathrm{n}=40-137)$. Prediction studies including large patient groups are needed to obtain reliable results. A multicenter retrospective omalizumab study including 470 patients investigated several possible predictors of treatment response and recurrence (D-dimer, disease duration, UAS7, total IgE level, anti-TPO positivity). In this study, $70.2 \%$ of the patients were omalizumab responders, $20.2 \%$ were partial responders, and $9.6 \%$ were nonresponders. Urticaria recurred in $66.3 \%$ of patients within the first 3 months after treatment discontinuation. It was shown that treatment response was better in patients with high total IgE level and that recurrence was more likely in patients with longer disease duration. ${ }^{24}$ These findings are very similar to our results in terms of treatment responses to omalizumab, recurrence rate (66.3\% vs. $65.4 \%)$, and predictor analysis (Table 6). Both studies demonstrated that total IgE level may be a predictor of treatment response and that pre-treatment disease duration may be a predictor of disease recurrence. A distinguishing feature of our study is our analysis of the influence of CRP, aeroallergen SPT positivity, and presence of angioedema on omalizumab treatment response and urticaria recurrence after discontinuation. CRP level, aeroallergen SPT positivity, and angioedema were not significantly associated with treatment response and urticaria recurrence in our study. Patients with high anti-TPO showed significantly poorer treatment response $(p=0.025)$ and early recurrence was less common among patients with skin prick test positivity for aeroallergens $(p=0.047)$. These new data should be confirmed in studies with larger patient samples.

In our study, 37 patients who were classified as partial responders or nonresponders to omalizumab were treated with omalizumab, sgAH, cyclosporine, and methotrexate as combined therapy or monotherapy. The drugs used most commonly in combined therapy were sgAH and omalizumab (90.6\% and $87.5 \%$, respectively). Half of the patients who started cyclosporine were unable to continue because it was not effective and/or caused severe adverse effects. Cyclosporine was ineffective in $25 \%$ of patients, and despite using a low dose $(2.5 \mathrm{mg} / \mathrm{kg} /$ day $)$, treatment was discontinued in $41.6 \%$ of patients due to severe adverse effects. The high rate of cyclosporine-related adverse effects observed (elevated blood pressure, hirsutism, hyperlipidemia, gingival hypertrophy) in our study was similar to rates reported in other clinical studies. In another study investigating the efficacy of cyclosporine in the treatment of CSU $(n=120)$, treatment was discontinued in $16.5 \%$ of patients due to adverse effects (abdominal pain and/ or diarrhea, peripheral neuropathy, or severe headache). ${ }^{8}$ In a review of the effectiveness of cyclosporine in chronic urticaria, adverse effects (hypertension, abnormal serum creatinine, gastrointestinal symptoms, headache, hirsutism, infection, paresthesia) were reported in $57 \%$ of patients receiving moderate-dose cyclosporine. ${ }^{9}$ Although the EAACI/GA ${ }^{2}$ LEN/EDF/ WAO guideline ${ }^{3}$ for CSU recommends cyclosporine as the first option in patients who are nonresponsive to omalizumab, its use in this area is limited to a great extent by severe adverse effects and the risk for lymphoproliferative disease with longterm use. ${ }^{25}$ Despite a few promising retrospective studies conducted in small series that suggest methotrexate is beneficial and safe in CSU, ${ }^{10,11}$ methotrexate had no benefit compared to a placebo according to a meta-analysis that included 104 patients in 2 placebo-controlled studies investigating the effectiveness of methotrexate added to antihistamine in antihistamine-resistant CSU. ${ }^{26}$ In contrast to this meta-analysis, in our study we observed that the addition of methotrexate benefited a large proportion $(77.7 \%)$ of patients who did not respond to combined therapy (Table 5). Safety profiles were similar in both studies; methotrexate was well tolerated by patients and there were no life-threatening systemic reactions. The most common adverse reactions in both studies were slight increase in liver function tests, nausea, and vomiting. According to our results, using methotrexate as an add-on therapy, in combination with antihistamine, or as monotherapy may be beneficial in cases of CSU resistant to combined therapies. Although in our study the efficacy appeared similar in those who tolerated cyclosporine and methotrexate as mono or combination therapy (75\% vs. $79.8 \%$, respectively), patients who received cyclosporine had a higher rate of adverse effects $(41.7 \%$ vs. $11.1 \%$, respectively) and subsequent discontinuation (50\% vs. $20.3 \%$, respectively) and reported more serious adverse events than patients treated with methotrexate (Table 5).

Studies investigating responses to combined therapy for CSU are vanishingly rare. In one clinical trial, 21 patients with CSU who were nonresponsive to omalizumab $(300 \mathrm{mg} / \mathrm{ev}-$ ery 4 weeks) and cyclosporine $(3 \mathrm{mg} / \mathrm{kg} /$ day) were given the drugs in combination. Treatment response (UAS7 <6) was reported in $76.1 \%$ of the patients after 4 months of treatment and there was no increase in adverse effects associated with combined use of the drugs. ${ }^{12}$

On evaluation of the overall treatment distribution in the 126 patients examined in our study, it was observed that $70.6 \%$ of patients received omalizumab monotherapy, $25.4 \%$ received combined therapy, and $4 \%$ received monotherapy with cyclosporine or methotrexate. According to our results, $96 \%$ of the 126 patients who received combined therapy or monotherapy responded to treatment. Treatment responses were comparable in patients treated with monotherapy and those that received combined therapy. 
Limitations of this study are the small number of patients taking cyclosporine and methotrexate and the lack of complete laboratory data for each patient.

In conclusion, our findings indicate that omalizumab monotherapy is at least as effective in real life as in placebo-controlled trials. Patients with high total IgE level may respond better to omalizumab. Although omalizumab monotherapy was effective in $66.9 \%$ of patients, a treatment period of 6 months was insufficient for two-thirds of those patients. Continuing omalizumab treatment for longer than 6 months may reduce the risk of recurrence after treatment discontinuation in patients with longer disease duration ( $>1$ year in particular). In patients with partial response to omalizumab and sgAH therapy, adding methotrexate or cyclosporine to the existing treatment regimen may be more beneficial than discontinuing omalizumab. Methotrexate appears to be a good alternative to cyclosporine in patients who show nonresponse or partial response to omalizumab and antihistamine up-dosing therapy.

\section{Acknowledgements}

None

\section{Conflict of interest}

None

\section{Source of funding with grant numbers None}

\section{References}

1. Maurer M, Weller K, Bindslev-Jensen C, Giménez-Arnau A, Bousquet PJ, Bousquet J, et al. Unmet clinical needs in chronic spontaneous urticaria. A GA²LEN task force report. Allergy. 2011;66(3):317-30.

2. Guillén-Aguinaga S, Jáuregui Presa I, Aguinaga-Ontoso E, Guillén-Grima F, Ferrer M. Updosing nonsedating antihistamines in patients with chronic spontaneous urticaria: a systematic review and meta-analysis. $\mathrm{Br}$ J Dermatol. 2016;175(6):1153-65.

3. Zuberbier T, Aberer W, Asero R, Abdul Latiff AH, Baker D, Ballmer-Weber $\mathrm{B}$, et al. The EAACI/GA ${ }^{2} \mathrm{LEN} / \mathrm{EDF} / \mathrm{WAO}$ guideline for the definition, classification, diagnosis and management of urticaria. Allergy. 2018;73(7): 1393-414.

4. Bérard F, Ferrier Le Bouedec MC, Bouillet L, Reguiai Z, Barbaud A, Cambazard $\mathrm{F}$ et al. Omalizumab in patients with chronic spontaneous urticaria nonresponsive to $\mathrm{H} 1$-antihistamine treatment: results of the phase IV open-label SUNRISE study. Br J Dermatol. 2019;180(1):56-66.

5. Kaplan A, Ledford D, Ashby M, Canvin J, Zazzali JL, Conner E, et al. Omalizumab in patients with symptomatic chronic idiopathic/ spontaneous urticaria despite standard combination therapy. J Allergy Clin Immunol. 2013;132(1):101-9.

6. Saini SS, Bindslev-Jensen C, Maurer M, Grob JJ, Bülbül Baskan E, Bradley MS, et al. Efficacy and Safety of Omalizumab in Patients with Chronic Idiopathic/Spontaneous Urticaria who Remain Symptomatic on H1 Antihistamines: A Randomized, Placebo-Controlled Study. J Invest Dermatol. 2015;135(3):925.
7. Maurer M, Rosén K, Hsieh HJ, Saini S, Grattan C, Gimenéz-Arnau A, et al. Omalizumab for the treatment of chronic idiopathic or spontaneous urticaria. N Engl J Med. 2013;368:924-35.

8. Kessel A, Toubi E. Cyclosporine-A in severe chronic urticaria: the option for long-term therapy. Allergy. 2010;65(11):1478-82.

9. Kulthanan K, Chaweekulrat P, Komoltri C, Hunnangkul S, Tuchinda P, Chularojanamontri L, et al. Cyclosporine for Chronic Spontaneous Urticaria: A Meta-Analysis and Systematic Review. Allergy Clin Immunol Pract. 2018;6(2):586-99.

10. Sagi L, Solomon M, Baum S, Lyakhovitsky A, Trau H, Barzilai A. Evidence for methotrexate as a useful treatment for steroid-dependent chronic urticariaActa Derm Venereol. 2011;91(3):303-6.

11. Perez A, Woods A, Grattan CE. Methotrexate: a useful steroid-sparing agent in recalcitrant chronic urticaria. Br J Dermatol. 2010;162(1):191-4.

12. Sánchez J, Alvarez L, Cardona R. Cyclosporine and omalizumab together: A new option for chronic refractory urticaria. J Allergy Clin Immunol Pract. 2020; 8(6):2101-3.

13. Serhat Inaloz H, Ozturk S, Akcali C, Kirtak N, Tarakcioglu M. Low-dose and short-term cyclosporine treatment in patients with chronic idiopathic urticaria: a clinical and immunological evaluation J Dermatol. 2008;35(5): 276-82.

14. Alizadeh Aghdam M, van den Broek F, Rijken F, Knulst AC, Röckmann H. High-dose omalizumab use in patients with chronic spontaneous urticaria. J Allergy Clin Immunol Pract. 2020;8(4):1426-7.

15. Dati F, Ringel KP. Reference values for serum IgE in healthy nonatopic children and adults. Clin Chem 1982;28(7):1556.

16. Ghazanfar MN, Sand C, Thomsen SF. Effectiveness and safety of omalizumab in chronic spontaneous or inducible urticaria: evaluation of 154 patients. Br J Dermatol. 2016;175(2):404-6.

17. Salman A, Ergun T, Gimenez-Arnau AM. Real-life data on the effectiveness and safety of omalizumab in monotherapy or combined for chronic spontaneous urticaria: a retrospective cohort study. J Dermatolog Treat. 2020;31(2):204-9.

18. Ghazanfar MN, Holm JG, Thomsen SF. Effectiveness of omalizumab in chronic spontaneous urticaria assessed with patient-reported outcomes: a prospective study. J Eur Acad Dermatol Venereol. 2018:32(10):1761-7.

19. Serarslan G, Uzun M, Doğramacı AÇ, Çelik E. Angioedema is an unfavorable factor for the response to omalizumab in chronic spontaneous urticaria: A retrospective study. Dermatol Ther. 2019;32(1):e12752.

20. Weller K, Ohanyan T, Hawro T, Ellrich A, Sussman G, Koplowitz J, et al Total IgE levels are linked to the response of chronic spontaneous urticaria patients to omalizumab. Allergy. 2018;73(12):2406-8.

21. Straesser MD, Oliver E, Palacios T, Kyin T, Patrie J, Borish L, et al Serum IgE as an immunological marker to predict response to omalizumab treatment in symptomatic chronic urticaria. J Allergy Clin Immunol Pract. 2018;6(4):1386-8.

22. Magen E, Chikovani T, Waitman DA, Kahan NR. Factors related to omalizumab resistance in chronic spontaneous urticaria. Allergy Asthma Proc. 2019;40(4):273-8.

23. Ertas R, Ozyurt K, Ozlu E, Ulas Y, Avci A, Atasoy M, et al. Increased IgE levels are linked to faster relapse in patients with omalizumab-discontinued chronic spontaneous urticaria. J Allergy Clin Immunol. 2017;140(6): 1749-51.

24. Marzano AV, Genovese G, Casazza G, Fierro MT, Dapavo P, Crimi $\mathrm{N}$, et al. Predictors of response to omalizumab and relapse in chronic spontaneous urticaria: a study of 470 patients. J Eur Acad Dermatol Venereol. 2019;33(5):918-24.

25. Gutierrez-Dalmau A, Campistol JM. Immunosuppressive therapy and malignancy in organ transplant recipients: a systematic review. Drugs. 2007;67(8):1167-98.

26. Patil AD, Bingewar G, Goldust M. Efficacy of methotrexate as add on therapy to $\mathrm{H} 1$ antihistamine in difficult to treat chronic urticaria: A systematic review and meta-analysis of randomized clinical trials. Dermatol Ther. 2020:e14077. 